\title{
Optimization of PI Controller using PSO for Power Electronic Converter
}

\author{
B.Achiammal ${ }^{1}$, R.Kayalvizhi, $^{2}$ \\ ${ }^{I}$ Electronics and Instrumentation Engineering, Annamalai University, India. \\ ${ }^{2}$ Electronics and Instrumentation Engineering, Annamalai University, India.
}

\begin{abstract}
DC-DC converters are widely used in application such as computer peripheral power supplies, car auxiliary power supplies and medical equipment's. Positive output elementary Luo converter performs the conversion from positive source voltage to positive load voltage. Due to the time-varying and switching nature of the power electronic converters, their dynamic behavior is highly non-linear. Conventional controllers are incapable of providing good dynamic performance and hence optimized techniques have been developed to tune the PI parameter. In this work, Particle Swarm Optimization (PSO) is developed for PI optimization. Simulation results show that the performances of PSO-PI controllers are better than those obtained by the classical ZN-PI controller.
\end{abstract}

Keywords: PI controller, DC-DC converter, positive elementary Luo converter, particle swarm optimization and soft computing technique

\section{INTRODUCTION}

Many industrial applications require power from variable DC voltage sources. DC-DC converters convert fixed DC input voltage to a variable DC output voltage for use in such applications. DC-DC converters are also used as interface between DC systems of different voltage levels. Positive output elementary Luo converter is a recently developed subset of the DC-DC converters. This converter provides positive load voltage for positive supply voltage. Luo converters overcome the effects of the parasitic elements that limit the voltage conversion ratio. These converters in general have complex non-linear modes with parameter variation problems. PI controllers do not provide satisfactory response for these converters which are time varying systems. Hence optimized techniques are used for regulating the positive output elementary Luo converter. In this work, PI controller, PSO based PI controller is designed and simulated for the above Luo converter. The performance indices used is Integral Squared Error (ISE) and Integral Absolute Error (IAE).

\section{MODELLING OF POSITIVE OUTPUT ELEMENTARY LUO CONVERTER}

A positive output elementary Luo converter (Fig.1) performs step-up/step-down conversions from positive input DC voltage to positive output DC voltage. The voltage transfer ratio of the above converter is $(\mathrm{k} /(1-\mathrm{k}))$ where $\mathrm{k}$ is the duty ratio. The circuits (Fig.2 and Fig.3) for the switch-on and switch-off modes of the chosen converter are developed using a state-space approach. At this point, these two models are averaged over a single switching period $\mathrm{T}$ using a state-space averaging technique.

The state variables are:

$\mathrm{X}_{1}=\mathrm{i}_{\mathrm{L} 1}, \mathrm{X}_{2}=\mathrm{i}_{\mathrm{L} 2}, \mathrm{X}_{3}=\mathrm{V}_{\mathrm{o}}, \mathrm{X}_{4}=\mathrm{V}_{\mathrm{co}}$

Using the above state variables, the system matrices $A_{1}$ and $A_{2}$, input matrices $B_{1}$ and $B_{2}$ and output matrices $\mathrm{C}_{1}$ and $\mathrm{C}_{2}$ are obtained.

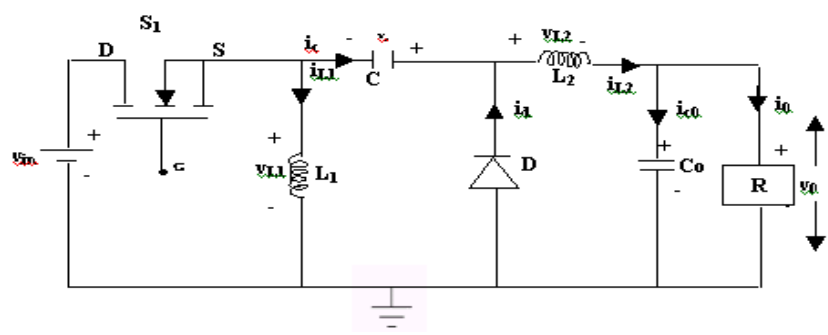

Fig. 1 Positive output elementary luo converter 


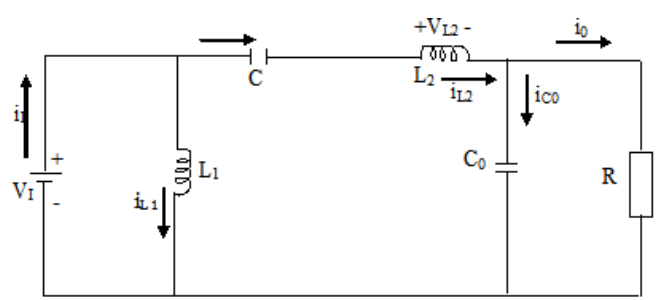

Fig.2 Positive output elementary Luo converter on mode

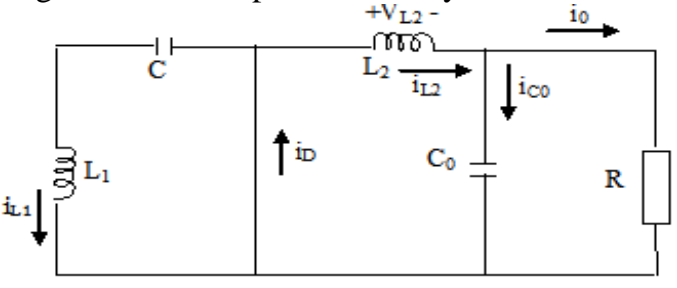

Fig.3 Positive output elementary Luo converter off mode

\section{DESIGN OF PI CONTROLLER}

The function of a controller is to receive the measured process variable (pv) and compare it with the set point (sp) to produce the actuating signal $(\mathrm{m})$ so as to drive the process variable to the desired value. Therefore the input to the controller is the error (sp-pv). It is also known as proportional plus reset controller. The actuating signal $\mathrm{m}(\mathrm{t})$ is related to the error $\mathrm{e}(\mathrm{t})$ by the equation.

$$
m(t)=K_{c} e(t)+\left(K_{c} / T_{i}\right) \int_{0}^{1} e(t) d t+m s
$$

Where $T_{i}$ is the integral time constant or reset time and 1/Ti is called repeats per minute. After a period of $T_{i}$ minutes for a constant error $\mathrm{E}$, the contribution of integral term is

$$
K_{c} / T \int_{0}^{T 1} e(t) d t=\left(K_{c} / T_{i}\right) E T_{i}=K_{c} E
$$

The integral action has repeated the response of the proportional action. Reset time is the time needed to repeat the initial proportional action change in its output. The integral action causes the controller output $m(t)$ to change as long as an error exists the process output. The transfer function of a PI controller

$$
\mathrm{G}_{\mathrm{c}}(\mathrm{s})=\mathrm{K}_{\mathrm{c}}\left[1+1 / \mathrm{T}_{\mathrm{i}} \mathrm{s}\right]
$$

\section{PARTICLE SWARM OPTIMIZATION}

Particle Swarm Optimization (PSO) was originally developed by Kennedy and Eberhart in 1995 is a population-based evolutionary algorithm. It was inspired by the social behavior of bird and fish schooling, and has been found to be robust in solving continuous nonlinear optimization problems.

In PSO, the swarm is initialized with a population of random solutions. Each particle in the swarm is a different possible set of the unknown parameters to be optimized. Representing a point in the solution space, each particle tries to adjust its flying toward a potential area according to its own flying experience and shares social information among particles. The objective is to efficiently search the solution space by swarming the particles toward the best fitting solution encountered in previous iterations with the intent of encountering better solutions through the course of the process and finally converging on a single minimum error solution.

For a multidimensional problem, the velocity and position of each particle in the swarm are updated using the following equations:

$$
\begin{aligned}
& \mathrm{V}_{\mathrm{i}}^{\mathrm{k}+1}=\mathrm{WV}_{\mathrm{i}}^{\mathrm{k}}+\mathrm{C}_{1} \operatorname{rand}\left(\text { pbest }_{\mathrm{i}}-\mathrm{S}_{\mathrm{i}}^{\mathrm{k}}\right)+\mathrm{C}_{2} \operatorname{rand}\left(\text { gbest }_{\mathrm{i}_{-}-} \mathrm{S}_{\mathrm{i}}^{\mathrm{k}}\right) \\
& \mathrm{X}_{\mathrm{i}}^{\mathrm{k}+1}=\mathrm{X}_{\mathrm{i}}^{\mathrm{k}}+\mathrm{V}_{\mathrm{i}}^{\mathrm{k}+1}
\end{aligned}
$$

Where

$\mathrm{V}_{\mathrm{i}}^{\mathrm{k}+1}$ is the velocity of the $i$ th particle at $(\mathrm{k}+1)$ iteration, $X i(\mathrm{k}+1)$ is the position of the $i$ th particle at $(\mathrm{k}+1)$ iteration, $\mathrm{w}$ is the inertial weight factor (weighting function), $\mathrm{C} 1$ and $\mathrm{C} 2$ are acceleration constants called cognitive learning rate and social learning rate respectively, rand is the random function in the range [0,1], pbest is the individual best position of the particle, gbest is the global best position of the swarm of the particles. The flow chart of PSO based PI control algorithm as shown in Fig.4 


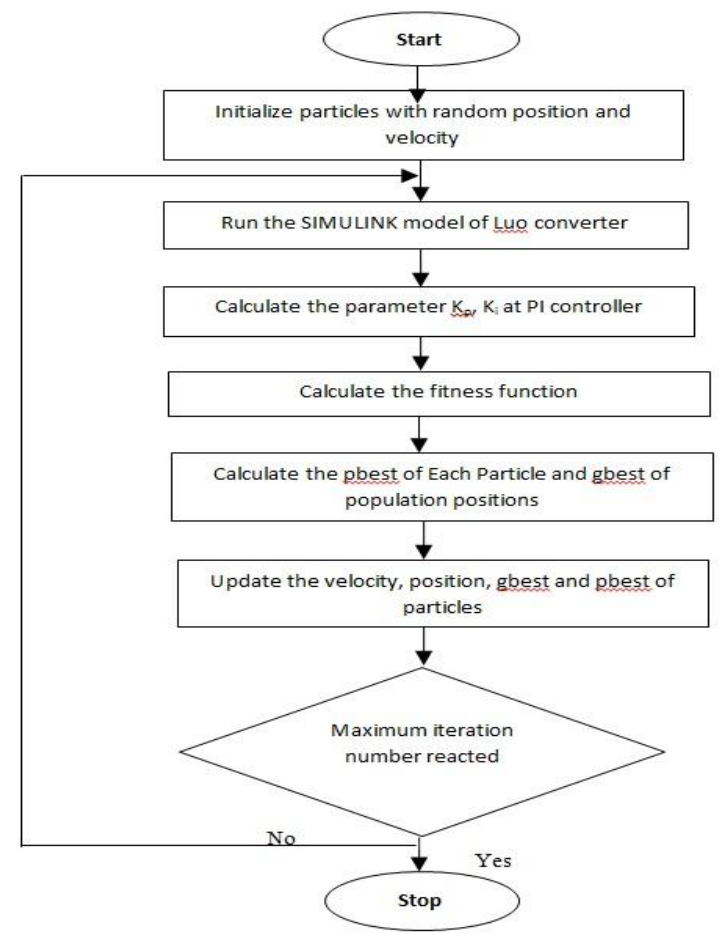

Fig.4 Flow chart of PSO

The weighting function, $w$ is responsible for dynamically adjusting the velocity of the particles, hence it is responsible for balancing between local and global search. Applying a large inertia weight at the start of the algorithm and decaying to a small value through the PSO execution makes the algorithm search globally at the beginning and locally at the end of the execution. The weighting function $w$ is calculated as:

$$
\mathrm{w}=\mathrm{w}_{\max }-\frac{\left(\mathrm{w}_{\max }-\mathrm{w}_{\min }\right) \cdot \text { iter }}{\text { iter }_{\max }}
$$

Here, $w_{\max }$ and $w_{\min }$ are the initial and final weights, iter is the current iteration time and iter ${ }_{\max }$ is the maximum number of iterations. The proposed Fitness function for the optimization of parameters of PI controller is defined as:

$$
\mathrm{F}(\mathrm{s})=\mathrm{w}_{\max }(\mathrm{Mp}+\mathrm{ISE}+\mathrm{IAE})+\mathrm{w}_{\min }\left(\mathrm{T}_{\mathrm{R}}+\mathrm{T}_{\mathrm{S}}\right)
$$

\section{Performance Indices}

The performance of a controller is best evaluated in terms of error criterion. In this work, controller performance is evaluated in terms of Integral Square Error (ISE) and Integral Absolute Error (IAE)

$$
\begin{aligned}
& \text { ISE }=\int_{0}^{t} e^{2} d t \\
& \text { IAE }=\int_{0}^{t}|e| d t
\end{aligned}
$$

The ISE and IAE weight the error with time and hence minimize the error values nearer to zero.

\section{Simulation Results}

The circuit parameters of the positive Output elementary Luo Converter are shown in the Table 1. The controller parameter values of the conventional ZN-PI and PSO-PI controllers are obtained. The responses of positive output elementary Luo controller using conventional ZN-PI and PSO-PI controller are shown in Figures 5,6,7 and 8. Table 2 shows the performance evaluation of positive output elementary Luo converter using conventional ZN-PI and PSO-PI controllers. Simulation results shows that PSO-PI controller will drastically reduce the overshoot, ISE and IAE values as compared to the conventional PI controller. 
TABLE. 1 CIRCUIT PARAMETERS OF POSITIVE OUTPUT ELEMENTARY LUO CONVERTER

\begin{tabular}{|c|c|c|}
\hline Parameter & Symbol & Value \\
\hline Input Voltage & $\mathrm{V}_{\text {in }}$ & $10 \mathrm{~V}$ \\
\hline Output Voltage & $\mathrm{V}_{\mathrm{o}}$ & $40 \mathrm{~V}$ \\
\hline Inductor & $\mathrm{L}$ & $100 \mu \mathrm{H}$ \\
\hline Capacitor & $\mathrm{C}$ & $5 \mu \mathrm{F}$ \\
\hline Frequency & $\mathrm{F}$ & $50 \mathrm{khz}$ \\
\hline Load resistor & $\mathrm{R}$ & $10 \Omega$ \\
\hline Duty ratio & $\mathrm{D}$ & 0.8 \\
\hline
\end{tabular}

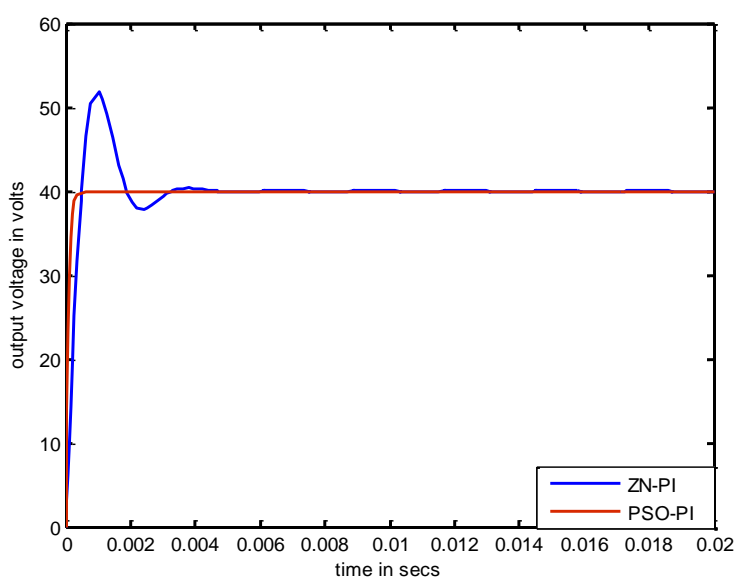

Fig. 5 Closed loop response of Positive Output Elementary Luo converter

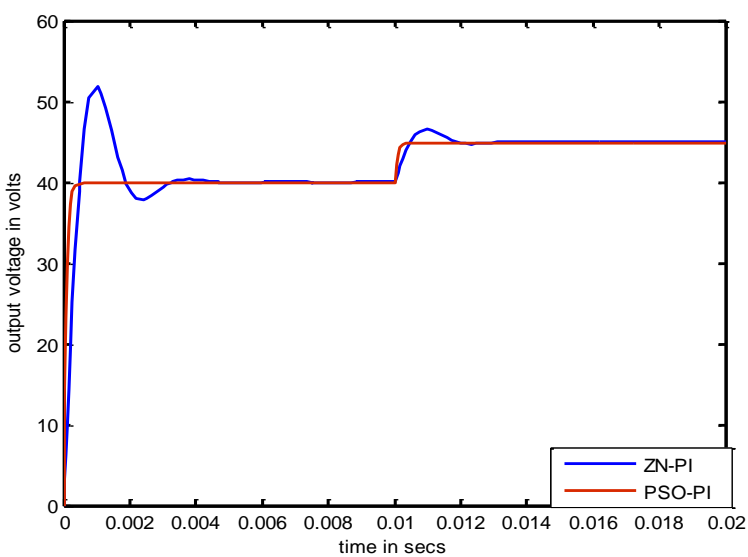

Fig. 6 Servo response of Positive Output Elementary Luo converter with increase in reference voltage from 40V-45V at $0.01 \mathrm{sec}$.

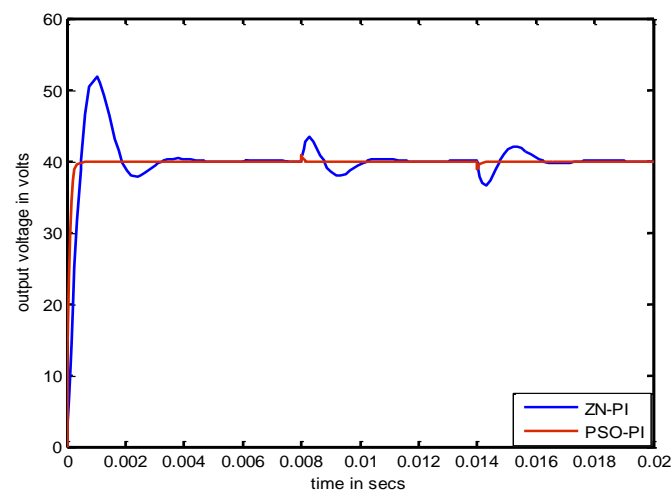

Fig. 7 Closed loop response of Positive Output Elementary Luo converter with sudden line disturbance from $10 \mathrm{~V}-11 \mathrm{~V}(10 \%)$ at $8 \mathrm{msec}$. and $10 \mathrm{~V}-9 \mathrm{~V}(10 \%)$ at $14 \mathrm{msec}$ 


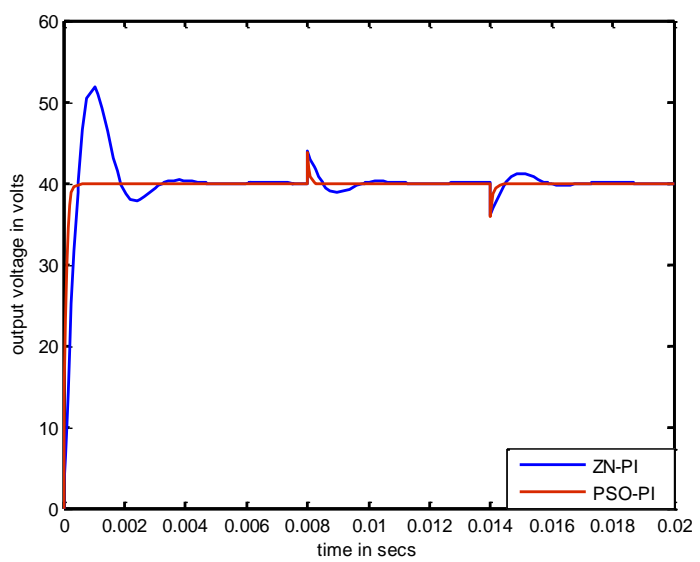

Fig. 8 Closed loop response of Positive Output Elementary Luo converter with sudden load disturbance from $10 \Omega-11 \Omega(10 \%)$ at $8 \mathrm{msec}$. and $10 \Omega-9 \Omega(10 \%)$ at $14 \mathrm{msec}$

\section{TABLE.2 PERFORMANCE EVALUATION OF POSITIVE OUTPUT ELEMENTARY LUO CONVERTER}

\begin{tabular}{|c|c|c|c|c|}
\hline \multirow{6}{*}{\multicolumn{2}{|c|}{ Startup Transient }} & Tuning Parameters & $\begin{array}{c}\text { ZN-PI } \\
\text { Controller }\end{array}$ & $\begin{array}{c}\text { PSO-PI } \\
\text { Controller }\end{array}$ \\
\hline & & Rising time (m.sec) & 0.5 & 0.45 \\
\hline & & Settling time (m.sec) & 4.7 & 1.2 \\
\hline & & & & \\
\hline & & ISE & 0.0771 & 0.0272 \\
\hline & & IAE & 0.0100 & 0.0039 \\
\hline \multirow{8}{*}{ Line Disturbance } & \multirow{4}{*}{ Line Increase $10 \%$} & Settling time (m.sec) & 3 & 0.7 \\
\hline & & Peak Overshoot $\%$ & 9.5 & 6.5 \\
\hline & & ISE & 0.0779 & 0.0274 \\
\hline & & IAE & 0.0110 & 0.0040 \\
\hline & \multirow{4}{*}{$\begin{array}{l}\text { Line decrease } \\
10 \%\end{array}$} & SETTLING TIME (M.SEC) & 2.8 & 0.8 \\
\hline & & Peak Overshoot $\%$ & 9.5 & 5.5 \\
\hline & & ISE & 0.0780 & 0.0275 \\
\hline & & IAE & 0.0110 & 0.0043 \\
\hline \multirow{8}{*}{ Load Disturbance } & \multirow{4}{*}{ Load increase $10 \%$} & Settling time (m.sec) & 4 & 2.1 \\
\hline & & PEAK OVERSHOOT $\%$ & 10 & 10.5 \\
\hline & & ISE & 0.0796 & 0.0278 \\
\hline & & IAE & 0.0123 & 0.0051 \\
\hline & \multirow{4}{*}{$\begin{array}{c}\text { Load decrease } \\
10 \%\end{array}$} & Settling time (m.sec) & 3.8 & 2.2 \\
\hline & & Peak Overshoot \% & 10 & 10.5 \\
\hline & & ISE & 0.0796 & 0.0288 \\
\hline & & IAE & 0.0123 & 0.0069 \\
\hline
\end{tabular}

\section{Conclusion}

In this work, Particle Swarm Optimization (PSO) algorithm is developed to tune the PI controller parameters which control the performance of positive output elementary Luo converter. The simulation results confirm that PI controller tuned with PSO algorithm rejects satisfactorily both the line and load disturbances. Also the results proved that PSO-PI controller gives the smooth response for the reference tracking and maintains the output voltage of the positive output elementary Luo converter according to the desired voltage.

\section{References}

[1]. Luo ,F.L, "Positive output Luo- converter voltage lift Technique”, IEE-EPAprocessdings, 146(4),July 1999,pp.415-432.

[2]. J.F.HUANG, F.B.DONG, “Modelling and Control on Isolated DC-DC Converter”, Power Electronics, voI.44, pp.87-89, April 2010.

[3]. M. Namnabat, M. Bayati Poodeh, S. Eshtehardiha, "Comparison the Control Methods in Improvement the Performance of the DC-DC Converter”, International Conference on Power Electronics 2007, (ICPE’07), pp.246-251, 2007.

[4]. Martin Plesnik., "Use of the State space averaging technique in fast steady state simulation algorithms for switching power converters", ieeexplore.ieee.org CCECE'2006.

[5]. J.You, S.B.Kang , "Generalized State Space Averaging based PWM Rectifier Modelling", Electrical Measurement \&Instrumentation vo1.46, pp.67-70, October 2009

[6]. R.Suresh Kumar, J.Suganthi, "Improving the Boost Converter PID Controller Performance Using Particle Swarm Optimization",EuropenJournal of Scientific Research, Vol.85 No3 September,2012,pp.327 - 335.

[7]. Y.Li and Z.C.Duan, "Optimization for parameter of PID based on PSO", Machinery \& Electronics, Issue: 9 pp. 26-28, 2004.

[8]. B.Nagaraj, P. Vijayakumar "A comparative study of PID controller tuning using GA, EP, PSO, and ACO", Journal of Automation, Mobile Robotics \& Intelligent Systems, volume 5, 2011

[9]. B. Nagaraj, S. Subha, B. Rampriya, "Tuning Algorithms for PID Controller using Soft Computing Techniques", IJCSNS International Journal of Computer Science and Network Security, vol,8,no.4,April 2008.

[10]. Ian Griffin, "On-line PID Controller Tuning using Genetic Algorithms", Dublin City University, 2003 